\title{
British Association of Oral and Maxillofacial Surgeons
}

By Peter A. Brennan, Deputy Chair of BAOMS Council and Patrick Magennis, Chair of BAOMS Council, British Association of Oral and Maxillofacial Surgeons, c/ o The Royal College of Surgeons of England, 35/43 Lincoln's Inn Fields, London, WC2A 3PE

W ho founded the society and why?

The British Association of Oral Surgeons (BAOMS) was founded by Norman Rowe in 1962, an international specialty leader at that time. The remit was both to develop the specialty and to bring surgeons together. The inaugural meeting was held at the Royal College of Surgeons of England later that year. The first President, Terrence Ward, and the first Council were elected by 75 founder members. Norman Rowe was appointed Honorary Secretary and John Hovell, Honorary Editor of the British Journal of Oral Surgery. All three names were well known and today many will have heard of Ward and Rowe, who have instruments named after them. Rowe also wrote a definitive trauma textbook with John Williams.

\begin{tabular}{l|r}
\hline $\begin{array}{l}\text { Table } 1 \text { Summary of BAOMS members by } \\
\text { category }\end{array}$ & Number \\
\hline Member type & 412 \\
\hline Fellows & 115 \\
\hline Fellows in Training & 316 \\
\hline Junior Trainees & 122 \\
\hline Members & 40 \\
\hline Associate Fellows & 138 \\
\hline Overseas Members & 174 \\
\hline Students & 99 \\
\hline Retired Fellows & 2 \\
\hline Retired Associate Fellows & 6 \\
\hline Free BJOMS (Charities) & 6 \\
\hline Honorary Fellows & $\mathbf{1 , 4 3 0}$ \\
\hline Total active members & \\
\hline
\end{tabular}

The Presidential Badge of Office was presented by the sister American Association AAOMS (American Association of Oral and Maxillofacial Surgeons) later in 1962 (pictured).

The Association was renamed BAOMS in 1985 to reflect the increasing complexity of the specialty. Since then, BAOMS and OMFS have grown exponentially and we are now firmly established as a surgical specialty for managing diseases of the oral cavity, jaws, neck, salivary gland and beyond with expertise in hard and soft tissue, microvascular free tissue transfer, sialendoscopy, cleft management and TMJ replacement to name a few.

\section{How many members are there and how do} you become one?

Total membership exceeds 1,400 (detailed in Table 1) with over 400 OMFS consultants (Fellows) and 115 specialty registrars (Fellows in Training). Trainees of all levels and specialists on the oral surgery (held by the GDC) and OMFS (held by the GMC) Specialist Lists are welcome to join BAOMS. We have members from the UK and across the world. New applications are circulated to Council on a regular basis for approval. It is pleasing to see so many young trainees embarking on their dental or medical career applying to join BAOMS. For more information please visit the BAOMS website www.baoms.org.uk.

\section{What are the aims of the society?} BAOMS promotes the advancement of education, research and the development of OMFS in the UK and beyond. We also encourage and assist OMFS postgraduate education, study and research. We support

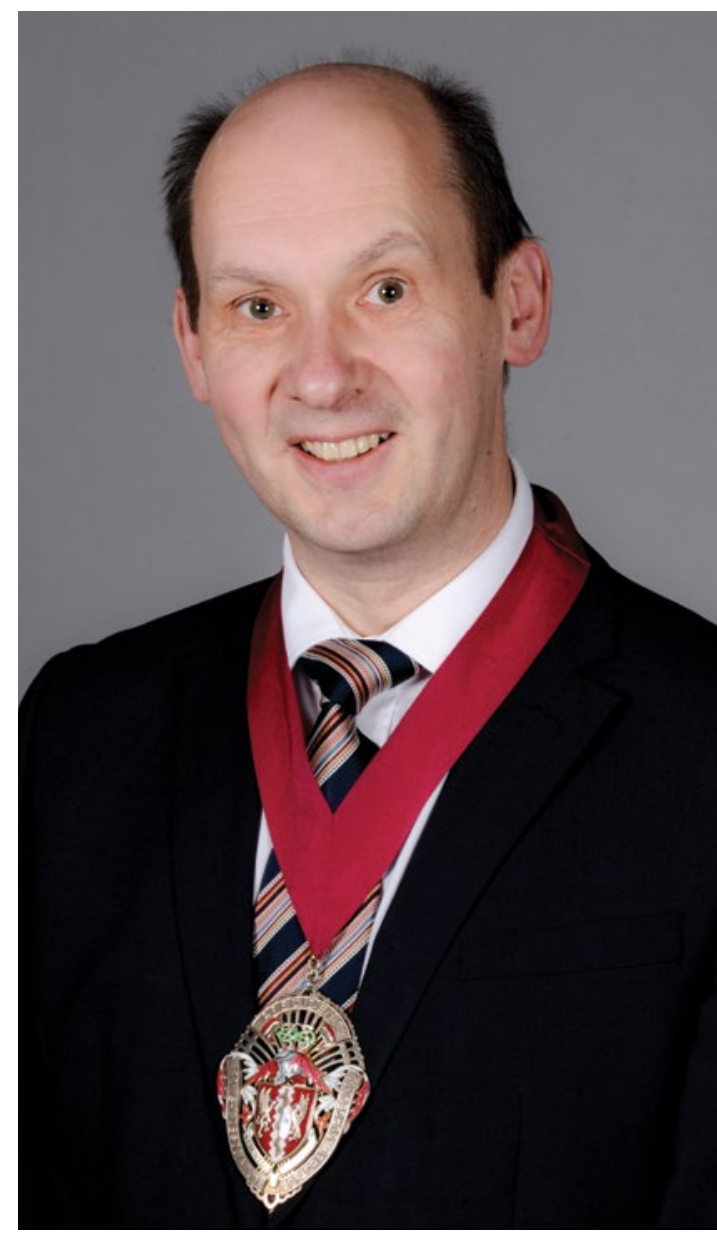

Peter A. Brennan wearing the Presidential Badge of Office during his year as BAOMS President in 2016

trainees during their second degree (including student bursaries) and provide colleagues with advice and support as needed. BAOMS has no regulatory role.

What services do you provide your members?

The Association's Journal, BJOMS is widely read and sent to members ten times a year as well as being available online (www. bjoms.com). An Annual Scientific Meeting is organised by the elected President for that year. Other meetings, courses and initiatives are held throughout the year. BAOMS appoints regional professional advisors across the UK, and also contributes to the Specialty Advisory Committees (SAC) in OMFS and oral surgery.

What are the society's greatest achievements? Following BAOMS' influence, dual qualification in both medicine 
4 and dentistry became mandatory in the late 1980s to ensure colleagues were adequately prepared to deal with increasingly complex pathology and surgery. To comply with the other surgical specialties, the requirement of basic general surgical training was facilitated by BAOMS in conjunction with the Royal Surgical Colleges. The need for formal assessment in surgery was also mandated, initially through the Fellowship of the Royal College of Surgeons (FRCS) examination, and more recently (from January 2004) the Intercollegiate Membership (MRCS) examination. The FRCS has now become the specialty exit examination.

OMFS was therefore formally established as one of the nine UK surgical specialities in 1994 (there are now ten). With established surgical recognition, OMFS also continues to flourish and push the boundaries in many areas such as virtual simulation. BAOMS is a strong advocate of equality and diversity, actively promoting women and ethnic minorities.
What does the society have planned for the next couple of years?

BAOMS is currently leading an exciting new national project - Quality Outcomes in OMFS (QOMS) to provide prospective audited data on patient and individual OMFS unit outcomes across the UK. To date, OMFS currently does not have any readily available validated outcome data that could be used to benchmark individual hospital departments disciplines showing that candidates who sit the Part A MRCS surgery exam (an entrance requirement to gain a specialty registrar appointment for all ten surgical specialties) at an earlier stage (in their FY1 year), perform better than those in FY2.

Raising awareness of the scope of OMFS particularly in medical schools where students have only limited or no exposure is important to help inspire junior doctors

\section{'Raising awareness of the scope of OMFS is important to help inspire junior doctors'}

and consultants, so this project is timely.

We are trying to reduce the long

arduous OMFS training pathway perhaps by attempting to remove the need for the second medical foundation year (FY2) after gaining a medical degree. We have led and published research from across surgical to pursue a career in the specialty. Finally, OMFS is a leader in human factors awareness to help improve patient safety, team working and morale, and we are likely to further develop this area in the next few years for the benefit of both our members and wider healthcare. 